\title{
ON CRITERIA OF EXISTENCE FOR NONLINEAR KATUGAMPOLA FRACTIONAL DIFFERENTIAL EQUATIONS WITH $p$-LAPLACIAN OPERATOR
}

\author{
YACINE ARIOUA AND Li MA*
}

\begin{abstract}
This paper is devoted to establishing vital criteria of existence and uniqueness for a class of nonlinear Katugampola fractional differential equations (KFDEs) with $p$-Laplacian operator subjecting to mixed boundary conditions. The reasoning is inspired by diverse classical fixed point theory, such as the Guo-Krasnosel'skii type fixed point principle and Banach contraction theorem. Additionally, several expressive examples are afforded to show the effectiveness of our theoretical results.
\end{abstract}

Mathematics subject classification (2020): 26A03, 34A12, 37C25.

Keywords and phrases: Katugampola fractional calculus, fixed point theorems, existence and uniqueness, $p$-Laplacian operator.

\section{REFERENCES}

[1] B. Ahmad, A. Alsaedi, S. K. Ntouyas, J. Tariboon, Hadamard-type Fractional Differential Equations, Inclusions and Inequalities, Switzerland, Springer International Publishing, 2017.

[2] Z. B. BAI, H. S. Lü, Positive solutions for boundary value problem of nonlinear fractional differential equation, J. Math. Anal. Appl, 2005, 311 (2): 495-505.

[3] B. Basti, Y. ARIOUA, N. Benhamidouche, Existence and uniqueness of solutions for nonlinear Katugampola fractional differential equations, J. Math. Appl, 2019, 42: 35-61.

[4] T. Y. Chen, W. B. LiU, An anti-periodic boundary value problem for the fractional differential equation with a p-Laplacian operator, Appl. Math. Lett, 2012, 25 (11): 1671-1675.

[5] R. GARRAPPA, Stability-preserving high-order methods for multiterm fractional differential equations, Internat. J. Bifur. Chaos, 2012, 22 (4): 1250073.

[6] A. Granas, J. Dugundj, Fixed Point Theory, New York, Springer-Verlag, 2003.

[7] D. Guo, V. Lakshmikantham, Nonlinear Problems in Abstract Cones, San Diego, Academic Press, 1988.

[8] Z. L. HAN, H. L. LU, C. ZHANG, Positive solutions for eigenvalue problems of fractional differential equation with generalized p-Laplacian, Appl. Math. Comput, 2012, 257: 526-536.

[9] R. Hilfer, Applications of Fractional Calculus in Physics, Singapore, World Scientific, 2000.

[10] H. Jafari, D. Baleanu, H. Khan, R. A. Khan, A. Khan, Existence criterion for the solutions of fractional order p-Laplacian boundary value problems, Bound. Value Probl, 2015, 2015: 164.

[11] U. N. Katugampola, New approach to a genaralized fractional integral. Appl. Math. Comput, 2011, 218 (3): 860-865.

[12] U. N. KatUgampola, A new approach to generalized fractional derivatives, Bull. Math. Anal. Appl, 2014, 6 (4): 1-15.

[13] H. Khan, W. Chen, H. G. Sun, Analysis of positive solution and Hyers-Ulam stability for a class of singular fractional differential equations with $p$-Laplacian in Banach space, Math. Methods Appl. Sci, 2018, 41 (9): 3430-3440.

[14] A. A. Kilbas, H. M. SRivastava, J. J. Trujillo, Theory and Applications of Fractional Differential Equations, Amsterdam, Elsevier, 2006. 
[15] X. P. LIU, M. JIA, W. G. GE, The method of lower and upper solutions for mixed fractional four-point boundary value problem with p-Laplacian operator, Appl. Math. Lett, 2017, 65: 56-62.

[16] L. MA, C. P. LI, On Hadamard fractional calculus, Fractals, 2017, 25 (3): 1750033.

[17] L. MA, C. P. LI, On finite part integrals and Hadamard-type fractional derivatives, J. Comput. Nonlinear Dynam, 2018, 13 (9): 090905.

[18] L. MA, Comparison theorems for Caputo-Hadamard fractional differential equations, Fractals, 2019, 27 (3): 1950036.

[19] L. MA, Blow-up phenomena profile for Hadamard fractional differential systems in finite time, Fractals, 2019, 27 (6): 1950093.

[20] L. MA, On the kinetics of Hadamard-type fractional differential systems, Fract. Calc. Appl. Anal, 2020, 23 (2): 553-570.

[21] L. MA, C. C. LiU, R. L. LiU, B. WANG, Y. X. ZHU, On fractional mean value theorems associated with Hadamard fractional calculus and application, Fract. Differential Calc, 2020, 10 (2): 225-236.

[22] C. Milici, G. DRĂGĂnescu, J. A. T. MAChado, Introduction to Fractional Differential Equations, Switzerland, Springer International Publishing, 2019.

[23] K. Perera, R. P. Agarwal, D. O'Regan, Morse Theoretic Aspects of p-Laplacian Type Operators, Providence, American Mathematical Society, 2010.

[24] I. Podlubny, Fractional Differential Equations, San Diego, Academic Press, 1999.

[25] P. Pucci, R. ServadeI, On weak solutions for p-Laplacian equations with weights, Rendiconti Lincei-Matematica e Applicazioni, 2007, 18 (3): 257-267.

[26] H. G. Sun, Y. Zhang, D. Baleanu, W. Chen, Y. Q. Chen, A new collection of real world applications of fractional calculus in science and engineering, Commun. Nonlinear Sci. Numer. Simul, 2018, 64: 213-231.

[27] J. J. TAN, C. Z. CHENG, Existence of solutions of boundary value problems for fractional differential equations with p-Laplacian operator in Banach spaces, Numer. Funct. Anal. Optim, 2017, 38 (6): 738-753.

[28] F. WANG, L. S. LiU, Y. H. WU, A numerical algorithm for a class of fractional BVPs with pLaplacian operator and singularity-the convergence and dependence analysis, Appl. Math. Comput, 2020, 382: 125339.

[29] J. F. XU, J. Q. Jiang, D. O'Regan, Positive solutions for a class of p-Laplacian Hadamard fractional-order three-point boundary value problems, Mathematics, 2020, 8 (3): 308.

[30] W. G. YANG, Eigenvalue problems for a class of nonlinear Hadamard fractional differential equations with p-Laplacian operator, Math. Slovaca, 2020, 70 (1): 107-124. 